Original Research Paper

\title{
Production of Selenium-Enriched Yeast (Kluyveromyces marxianus) Biomass in a whey-based Culture Medium
}

\author{
${ }^{1}$ Nicolás Gurdo, ${ }^{2}$ Mario Calafat, ${ }^{1}$ Diego Gabriel Noseda and ${ }^{2}$ Isabel Gigli \\ ${ }^{I}$ Instituto de Investigaciones Biotecnológicas-Instituto Tecnológico de Chascomús (IIB -INTECH), \\ Universidad Nacional de San Martín (UNSAM) - Consejo Nacional de \\ Investigaciones Cientificas y Técnicas (CONICET), San Martín, Buenos Aires, Argentina \\ ${ }^{2}$ Facultad de Agronomía, Universidad Nacional de La Pampa, Santa Rosa, La Pampa, Argentina
}

\section{Article history}

Rceived: 21-04-2018

Revised: 6-06-2018

Accepted: 20-06-2018

Corresponding Author:

Isabel Gigli

Facultad de Agronomía

Universidad Nacional de La

Pampa, Ruta 35, Km 334 (6300)

Santa Rosa, La Pampa, Argentina

Email: igigli@agro.unlpam.edu.ar

\begin{abstract}
Two important aspects of agriculture intensification are the reduction in the concentration of specific soil minerals that affects livestock production and the increase of agricultural by-products, which produce environmental pollution. In this regard, whey - a cheese by-product-often is considered a wasted-product. Due to its lactose concentration, (4.5\%), when whey is discarded without treatment generates a high Biological Oxygen Demand (BOD) and a high Chemical Oxygen Demand (COD). Taking into account these two issues, we developed a whey-based culture medium to produce selenium-enriched Kluyveromyces biomass. Then, we evaluated the effect of its supplementation on calves blood selenium concentration. Kluyveromyces marxianus DSM 11954 and Kluyveromyces lactis DSM 3795 strains were used in this study. Different culture media were prepared using whey as a main component and supplemented with peptone, yeast extract, $\left(\mathrm{NH}_{4}\right)_{2} \mathrm{SO}_{4}$ and $\mathrm{K}_{2} \mathrm{HPO}_{4}$ as appropriate. In the selected whey culture medium, three sodium selenite concentrations between $10-30 \mu \mathrm{g} / \mathrm{mL}$ were tested to produce selenium-enriched biomass. After that, a scaled up to $5 \mathrm{~L}$ stirred-tank bioreactor was carried out to increase final yeast biomass levels. Finally, dietary supplementation experiments with selenium-enriched yeast were conducted to increase selenium content in calves. K. marxianus DSM 11954 showed a better growth performance than $K$. lactis DSM 3795 in a medium composed by whey, $\left(\mathrm{NH}_{4}\right)_{2} \mathrm{SO}_{4} 5 \mathrm{~g} / \mathrm{L}, \mathrm{K}_{2} \mathrm{HPO}_{4} 1 \mathrm{~g} / \mathrm{L}$ (pH 6.5) so, this strain was chosen to continue the experiments. The results showed that sodium selenite addition at $20 \mu \mathrm{g} / \mathrm{mL}$ was adequate to generate selenium-enriched biomass. Our study demonstrated that whey is an optimal and economical culture medium to produce selenium-enriched- yeast biomass. Also, we proved that 10 days of yeast-biomass supplementation raised blood-selenium level in calves.
\end{abstract}

Keywords: Whey, Selenium, Kluyveromyces Marxianus, Supplementation, Calves

\section{Introduction}

Population growth led to an intensification of agricultural production systems. As a consequence of agriculture management, some soils present a reduction of specific minerals concentration that affects livestock. For instance, some geographic areas, especially in semiarid regions, are lacking selenium (Gil et al., 2004; Mirlean et al., 2018). Even though selenium is required in low amounts (300 $\mu \mathrm{g}$ /dry matter intake), it is an essential microelement for livestock (National Research Council, 2001). Many enzymes require selenium as a cofactor, being one of particular interest the glutathione peroxidase, which catalyzes lipid hydroperoxides to hydroxy acids and water (Smith et al., 1974). Moreover, selenium is crucial for the correct function of the thyroid gland (Beckett et al., 1993). Cows with selenium deficiency are associated with immunological alteration, increasing placental retention and decreased milk production (Julien et al., 1976; Moeini et al., 2009). In 
calves, selenium deficiency causes a myodegenerative disorder called white muscle disease (Andrews et al., 1968) and retards growth rate (Gleed et al., 1983). Selenium is biologically active as selenium-containing amino acids, such as selenocysteine and selenomethionine, the latter being most commonly found in animals diet (Fairweather-Tait et al., 2010). Livestock can be supplemented with inorganic or organic selenium. It has been reported that organic selenium has a higher bioavailability and lower toxicity than the inorganic form in cows (Slavik et al., 2008; Brennan et al., 2011; Salman et al., 2013) and ewes (Hall et al., 2012).

Another aspect of intensification is the increase of agricultural by-products that contribute to environmental contamination. In this regard, whey - a derivative of the cheese industry - represents $80-90 \%$ of the total volume of milk entering the cheese process. Due to its high lactose concentration (4.5\%), whey is highly polluting (World Bank Group, 1998). Even when different alternatives have been proposed (e.g. animal feeding with no further process or dried whey production) whey is still discarded, causing a high environmental impact especially in developing countries where the drying process is not profitable. Yet, far from being a waste, whey is an economical culture medium due to its composition (Amado et al., 2016). It would provide an alternative use, if its lactose were utilized as a carbon source for the development of microorganisms. Commercial organic selenium is based on Saccharomyces cerevisiae, however, this yeast does not express lactase, an essential enzyme for lactose energy source. Therefore, in this study, we produced seleniumenriched Kluyveromyces biomass as an organic selenium for calves' supplementation in a whey-based culture media. Through this process, the reuse of an agroindustrial byproduct is achieved, avoiding in this way environmental contamination.

\section{Materials and Methods}

\section{Whey Composition}

Sweet whey was obtained from a local cheese maker factory in La Pampa, Argentina and stored at $-20^{\circ} \mathrm{C}$ until use. The characteristics of this whey are indicated in Table 1. The high lactose concentration in this medium increases the chances of biomass formation.

Table 1: Characteristics of the whey used for culture medium preparation

\begin{tabular}{lc}
\hline Parameter & Value \\
\hline Lactose $(\mathrm{g} / \mathrm{L})$ & 45.0 \\
Proteins $(\mathrm{g} / \mathrm{L})$ & 9.0 \\
Fat $(\mathrm{g} / \mathrm{L})$ & 6.6 \\
Total solids $(\mathrm{g} / \mathrm{L})$ & 68.0 \\
$\mathrm{pH}$ & 6.5 \\
Colour & Yellow \\
\hline
\end{tabular}

Depending on the experiment, medium components and salts were diluted directly in the sweet whey and then autoclaved at $121^{\circ} \mathrm{C}$ for $20 \mathrm{~min}$.

\section{Biological Material}

The type strains Kluyveromyces marxianus DSM 11954 and Kluyveromyces lactis DSM 3795 were purchased from the Leibniz-Institute DSMZ (German collection of microorganisms and cell culture). Competent yeast cells were prepared in YPD ( $1 \%$ yeast, $2 \%$ peptone, $2 \%$ dextrose and $2 \%$ agar, $\mathrm{w} / \mathrm{v}$ ) for $48 \mathrm{~h}$ and then were transferred into YPD liquid medium for another $24 \mathrm{~h}$. Incubations were performed at $28^{\circ} \mathrm{C}$.

\section{Determination of Kinetic and Stoichiometric Parameters in Rich Culture Media}

Kluyveromyces marxianus and K. lactis were cultured in Erlenmeyer flasks containing YPD and YPL ( $1 \%$ yeast, $2 \%$ peptone and $2 \%$ dextrose, w/v). The $\mathrm{pH}$ was adjusted to 5.5 with $\mathrm{HCl} 1 \mathrm{~N}$. The purpose was to compare kinetic (specific growth rate, $\mu$ ) and stoichiometric (biomass yield coefficient based on substrate consumption, $\mathrm{Y}_{\mathrm{x} / \mathrm{s}}$ ) parameters of Kluyveromyces strains in both media. Cultures were performed in an orbital shaker at $28^{\circ} \mathrm{C}$ and $250 \mathrm{rpm}$ and were sampled periodically during incubation for biomass level measurement. The optical density of culture samples was measured at $600 \mathrm{~nm}$ using a spectrophotometer and converted to dry cell weights (DCW, in $\mathrm{g} / \mathrm{L}$ ) with a previously calculated calibration curve in accordance to the formula: $\mathrm{OD}_{600 \mathrm{~nm}}=2.14 \times \mathrm{DCW}, \mathrm{R}^{2}=0.990$. Kinetic and stoichiometric parameters were obtained from the growth curves of both Kluyveromyces strains.

\section{Study of Kinetic Growth of Kluyveromyces marxianus in a Whey-based Culture Medium}

Four different culture media were prepared from sweet whey: 1.- whey without adding any nutrients $(\mathrm{pH}$ $6.5)$; 2.- whey, peptone $2 \%$ and yeast extract $1 \%$, w/v (pH 6.5); 3.- milk whey, peptone $0.5 \%$, yeast extract $0.25 \%$ and $\mathrm{K}_{2} \mathrm{HPO}_{4} 0.1 \%$, w/v (pH 6.5); 4.- whey, $\left(\mathrm{NH}_{4}\right)_{2} \mathrm{SO}_{4} \quad 0.5 \%$ and $\mathrm{K}_{2} \mathrm{PO}_{4} 0.1 \%$, w/v (pH 6.5). $K$. marxianus DSM 11954 was cultured in Erlenmeyer flasks containing such whey-based culture media at $28^{\circ} \mathrm{C}$ and $150 \mathrm{rpm}$. Kinetic (specific growth rate, $\mu$ ) and stequiometric (biomass yield, $\mathrm{Y}_{\mathrm{x} / \mathrm{s}}$ ) parameters were determined from growth curves of $K$. marxianus in each culture medium. The $\mathrm{pH}$ of the culture media was adjusted to 6.5 because whey was obtained at this value from the cheese maker factory.

\section{Production of Kluyveromyces Biomass in a whey- based Medium Supplemented with Selenium}

To study the correlation between selenium concentration in culture medium and the yeast growth 
rate, $K$. marxianus DSM 11954 was grown in a medium composed of whey, $\left(\mathrm{NH}_{4}\right)_{2} \mathrm{SO}_{4} \quad 0.5 \%$ and $\mathrm{K}_{2} \mathrm{PO}_{4} 0.1 \%$, w/v (pH 6.5) with different $\mathrm{Na}_{2} \mathrm{SeO}_{3}$ concentration: 0 $\mu \mathrm{g} / \mathrm{mL} ; 10 \mu \mathrm{g} / \mathrm{mL} ; 20 \mu \mathrm{g} / \mathrm{mL}$ and $30 \mu \mathrm{g} / \mathrm{mL}$. Incubations of the cultures were performed at $28^{\circ} \mathrm{C}$ and $150 \mathrm{rpm}$, withdrawing samples periodically during incubation for biomass quantification. Specific growth rate $(\mu)$ and biomass yield $\left(\mathrm{Y}_{\mathrm{x} / \mathrm{s}}\right)$ were determined from the growth curves of $K$. marxianus in the whey-based medium supplemented with selenium.

\section{Scaling up the production of Selenium-Enriched} Kluyveromyces Biomass

The scaling up of the production of seleniumenriched yeast was performed in a stirred-tank bioreactor applying a repetitive batch cultures. In order to obtain the inoculum for bioreactor fermentation, $K$. marxianus DSM 11954 cells grown on YPD agar plates were first cultured overnight in $20 \mathrm{~mL}$ YPD medium at $28^{\circ} \mathrm{C}$ and $250 \mathrm{rpm}$. The day after, $200 \mathrm{~mL}$ of YPD in a $1 \mathrm{~L}$ Erlenmeyer flask were inoculated with the overnight culture and incubated at $28^{\circ} \mathrm{C}$ and $250 \mathrm{rpm}$ until an OD600nm of $\sim 8$. Finally, this culture was used to inoculate $5 \mathrm{~L}$ of whey-based culture medium contained in a 6 L-BioFlo 110 bioreactor (New Brunswick Scientific; Edison, NJ). The stirred bioreactor was used in interface with the Biocommand Bioprocessing software (New Brunswick Scientific) for parameter control and data acquisition. Temperature was maintained at $28^{\circ} \mathrm{C}$ through the fermentation process. Furthermore, $\mathrm{pH}$ was hold at a value of 5 by adding $\mathrm{H}_{3} \mathrm{PO}_{4}(42 \% \mathrm{v} / \mathrm{v})$ and $\mathrm{NH}_{4} \mathrm{OH}(26 \% \mathrm{v} / \mathrm{v})$ which also served as nitrogen source. Dissolved Oxygen (DO) was controlled through agitation (maximum of $1200 \mathrm{rpm}$ ) and filter-sterilized $(0.22 \mu \mathrm{m})$ air supply. The $\mathrm{pH}$ was determined using a $\mathrm{pH}$ electrode (Mettler-Toledo $\mathrm{GmbH}$, Germany) and the oxygen concentration was measured with a polarographic probe (InPro6110/320, MettlerToledo $\mathrm{GmbH}$ ). Foam formation was avoided by the addition of $0.3 \%(\mathrm{v} / \mathrm{v})$ antifoam 289 (Sigma-Aldrich; St. Louis, MO). Fermentation samples were withdrawn throughout batch cultures with the purpose of evaluating biomass concentration and quantifying the yeast organic selenium.

\section{Chemical Determinations of the Yeast Biomass}

Organic selenium concentration was determined by Inductively Coupled Plasma-Optical Emission Spectroscopy (ICP-OES) in Kluyveromyces biomass obtained from bioreactor fermentations. Furthermore, total protein concentration and amino acid composition were evaluated in Kluyveromyces biomass obtained from fermentation. The analysis of total protein was performed by Kjeldahl method; and the amino acid composition by HPLC (Hewlett Packard Serie 1100) according to the procedures described in the AOAC Standards Development Animal assay.

\section{Effect of Dietary Supplementation with Selenium- Enriched Yeast in Calves}

The effect of dietary supplementation with seleniumenriched yeast on selenium blood level was studied in 6 calves. Animal management was performed under the approval of School of Agriculture, University of La Pampa. Animals were 90 day-old and weighed approximately $100 \mathrm{~kg}$. Selenium-enriched biomass was supplemented daily to the grain ration $(0.60 \mathrm{mg} \mathrm{Se} / \mathrm{animal})$ during 10 days. Blood samples were taken from the jugular of each calf before the dietary supplementation and the day after the treatment had finished. Blood selenium was measured by hydride generation atomic absorption spectrometry at EEA "Ing. Agr. Domingo R. Pasquale" Veterinary Diagnostics Service, at the National Institute of Agricultural Technology (INTA), Balcarce.

\section{Statistical Analysis}

A two-way ANOVA was used to compare the effect of time and medium conditions. The effect of selenium supplementation in calves was analysed by paired samples t-test. These analyses were done with the $\mathrm{R}$ Project for Statistical Computing.

\section{Results}

Kluyveromyces marxianus and Kluyveromyces lactis Growth in Rich Culture Media

In order to study the ability of two strains of Kluyveromyces to grow in lactose medium, we first evaluated the kinetic growth of $K$. marxianus DSM 11954 and $K$. lactis DSM 3795 in two rich culture media (YPD and YPL). As shown in Fig. 1, $K$. marxianus strain presented a similar growth pattern independently of the two culture media evaluated reaching a biomass level of 13.8 and $13.5 \mathrm{~g} \mathrm{DCW} / \mathrm{L}$ for YPD and YPL medium respectively. In this sense, in the presence of both carbon sources, the lag phase lasted $2 \mathrm{~h}$ and the exponential stage was extended by 9 $\mathrm{h}$ and this was followed by the deceleration phase that lasted until the incubation finished. In contrast, the growth kinetic of $K$. lactis DSM 3795 depended on the carbon source employed in the culture medium. In the control YPD medium, $K$. lactis exhibited a growth pattern similar to that observed with $K$. marxianus, but with a slightly extended lag phase. However, K. lactis biomass levels in YPL $(3.2 \mathrm{~g} \mathrm{DCW} / \mathrm{L})$ was significantly lower than the one obtained in YPD medium (13.1 g DCW/L). Moreover, the specific growth rate $(\mu)$ was different between Kluyveromyces species. 


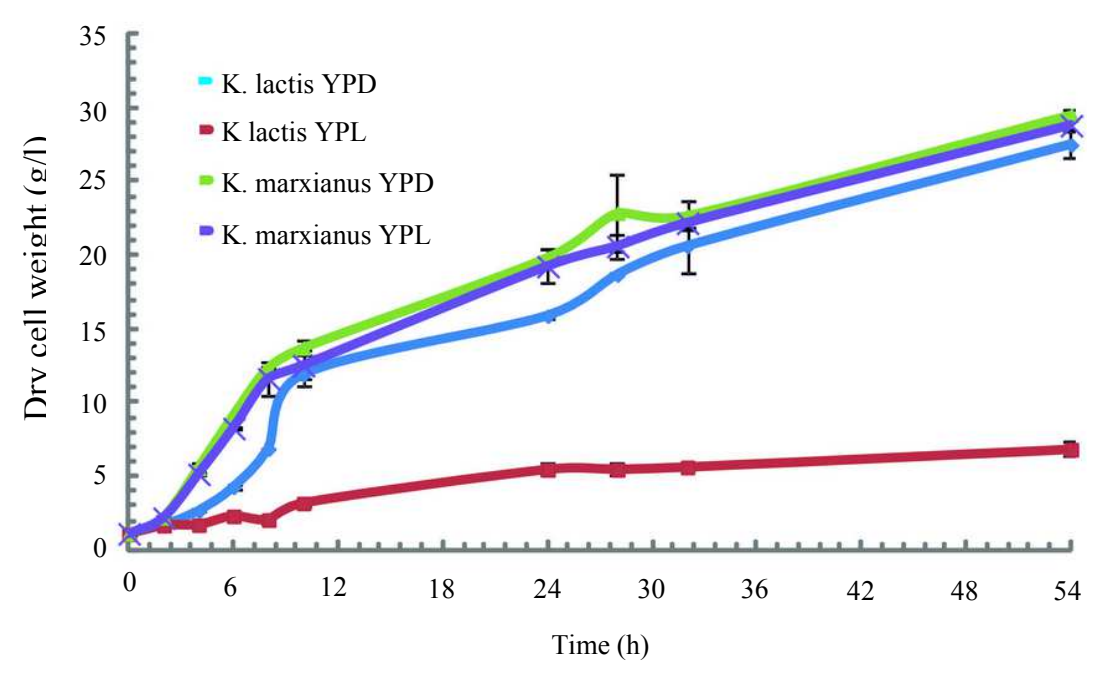

Fig. 1: Growth kinetics of Kluyveromyces marxianus DSM 11954 and Kluyveromyces lactis DSM 3795 in YPD medium (yeast extract $1 \%$, peptone $2 \%$ and dextrose $2 \%$ ) and YPL medium (yeast extract $1 \%$, peptone $2 \%$ and lactose $2 \%$ ).

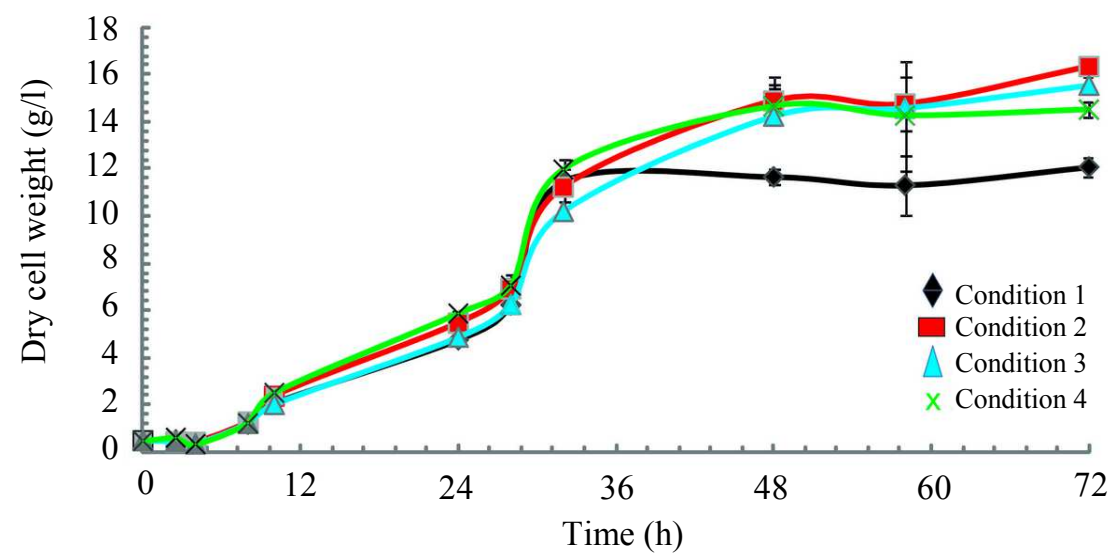

Fig. 2: Effect of whey-based culture media on Kluyveromyces marxianus DSM 11954 growth kinetics. Medium 1: Whey; Medium 2: whey, peptone $2 \%$, yeast extract $1 \%$; Medium 3 : whey, peptone $0.5 \%$, yeast extract $0.25 \%, \mathrm{~K} 2 \mathrm{HPO} 40.1 \%$; Medium 4 : whey, $\left(\mathrm{NH}_{4}\right)_{2} \mathrm{SO}_{4} 0.5 \%, \mathrm{~K}_{2} \mathrm{PO}_{4} 0.1 \%$.

As it is shown in Fig. 1, Kluyveromyces marxianus reached a specific rate of $0.36 \pm 0.01 \mathrm{~h}-1$ in YPD and $0.34 \pm 0.01 \mathrm{~h}-1$ in YPL. On the contrary, Kluyveromyces lactis specific rate was $0.23 \pm 0.01 \mathrm{~h}-1$ when it grew in YPD medium and $0.05 \pm 0.01 \mathrm{~h}-1$ in YPL. Due to these results, we chose $K$. marxianus strain to continue our studies.

\section{Growth Kinetics of Kluyveromyces marxianus in Culture Media based on Milk Whey}

The growth of $K$. marxianus DSM 11954 was evaluated in four different whey-based culture media: 1 . Whey; 2. whey, peptone $2 \%$, yeast extract $1 \%$, w/v; 3 . whey, peptone $0.5 \%$, yeast extract $0.25 \%, \mathrm{~K}_{2} \mathrm{HPO}_{4}$ $0.1 \%$, w/v; 4. whey, $\left(\mathrm{NH}_{4}\right)_{2} \mathrm{SO}_{4} 0.5 \%$ and $\mathrm{K}_{2} \mathrm{PO}_{4} 0.1 \%$, w/v. As shown in Fig. 2, K. marxianus presented a prolonged lag phase in all whey-based culture media evaluated. The first $24 \mathrm{~h}$ of incubation, growth kinetics and biomass production of $K$. marxianus were similar in all culture media tested $(4.76 \mathrm{~g} \mathrm{DCW} / \mathrm{L}, 5.46 \mathrm{~g}$ $\mathrm{DCW} / \mathrm{L}, 4.87 \mathrm{~g} \mathrm{DCW} / \mathrm{L}$ and $5.87 \mathrm{~g} \mathrm{DCW} / \mathrm{L}$ from medium 1 to 4). However, in the presence of whey alone, K. marxianus DSM 11954 reached the stationary phase earlier. Interestingly, when adding $\left(\mathrm{NH}_{4}\right)_{2} \mathrm{SO}_{4}$ $0.5 \%$ and $\mathrm{K}_{2} \mathrm{PO}_{4} 0.1 \%$, w/v (medium 4, Fig. 2), growth showed a similar rate compared with any of the two other enriched media (medium 2 and 3, Fig. 2). Maximum biomass was achieved at $72 \mathrm{~h}$ of incubation with culture media 1 (11 g DCW/L), 2 (16 g DCW/L) and $3(15 \mathrm{~g} \mathrm{DCW} / \mathrm{L})$. On the other hand, medium 4 reached maximum biomass (14 g DCW/L) at $48 \mathrm{~h}$ of incubation (Fig. 2). When specific growth rates were calculated, a similar performance in all medium $(0.08 \pm 0.01 \mathrm{~h}-1)$ was obtained. 


\section{Production of Selenium-Enriched Kluyveromyces Biomass in a Whey-based Medium}

Since medium 4 is an economical culture medium and $K$. marxianus showed to grow without restriction and similarly to conventional medium containing yeast extract and peptone, we used this media to scale the process. First, to obtain enriched-seleniumKluyveromyces- biomass, we studied the toxicity effect of sodium selenite concentration on the yeast growth rate. To do this, $K$. marxianus DSM 11954 was grown in medium 4 supplemented with four different $\mathrm{Na}_{2} \mathrm{SeO}_{3}$ concentrations: $0 \mu \mathrm{g} / \mathrm{mL} ; 10 \mu \mathrm{g} / \mathrm{mL} ; 20 \mu \mathrm{g} / \mathrm{ml}$ and 30 $\mu \mathrm{g} / \mathrm{mL}$. In order to shorten the delay phase, $K$. marxianus was grown in YPD overnight and then inoculated into the different selenium concentration media. As it is shown in Fig. 3, the presence of selenium in the media did not inhibit $K$. marxianus growth at any concentration. However, adding $30 \mu \mathrm{g} / \mathrm{mL}$ of $\mathrm{Na}_{2} \mathrm{SeO}_{3}$ to the medium resulted in a decrease of the maximum level of biomass compared to the other three media tested. When supplementing the whey-based culture medium with 10 and $20 \mu \mathrm{g} / \mathrm{mL}$ of $\mathrm{Na} 2 \mathrm{SeO} 3$, the maximum level of biomass reached was $9.6 \mathrm{~g} \mathrm{DCW} / \mathrm{L}$ and $9.9 \mathrm{~g} \mathrm{DCW} / \mathrm{L}$ respectively after $36 \mathrm{~h}$ of incubation. Specific growth rates varied lightly between culture media starting with a rate of $0.26 \pm 0.01 \mathrm{~h}^{-1}$ (in control condition, $0 \mu \mathrm{g} / \mathrm{mL}$ ) following by $0.25,0.24$ and $0.23 \pm 0.01 \mathrm{~h}^{-1}\left(10,20\right.$ and $30 \mu \mathrm{g} / \mathrm{mL}$ of $\mathrm{Na}_{2} \mathrm{SeO}_{3}$ respectively). Therefore, the whey-based culture medium supplemented with $20 \mu \mathrm{g} / \mathrm{mL}$ of $\mathrm{Na}_{2} \mathrm{SeO}_{3}$ was chosen for the scaling up of Kluyveromyces biomass production in stirred-tank bioreactor since it was the maximum selenium concentration that did not affect yeast growth.

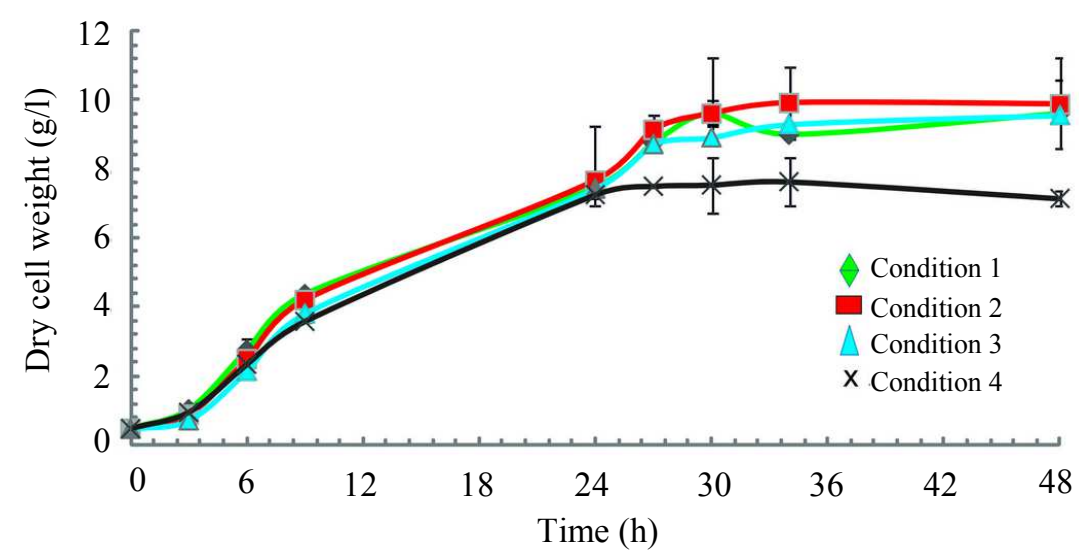

Fig. 3: Effect of sodium selenite concentration on Kluyveromyces marxianus DSM 11954 growth kinetics in a whey-based culture medium (whey, $\left(\mathrm{NH}_{4}\right)_{2} \mathrm{SO}_{4}$ and $\mathrm{K}_{2} \mathrm{PO}_{4}$ ) supplemented with four different $\mathrm{Na}_{2} \mathrm{SeO}_{3}$ concentrations: $0 \mu \mathrm{g} / \mathrm{mL}$ (Medium 1); 10 $\mu \mathrm{g} / \mathrm{mL}$ (Medium 2); $20 \mu \mathrm{g} / \mathrm{mL}$ (Medium 3) and $30 \mu \mathrm{g} / \mathrm{mL}$ (Medium 4)

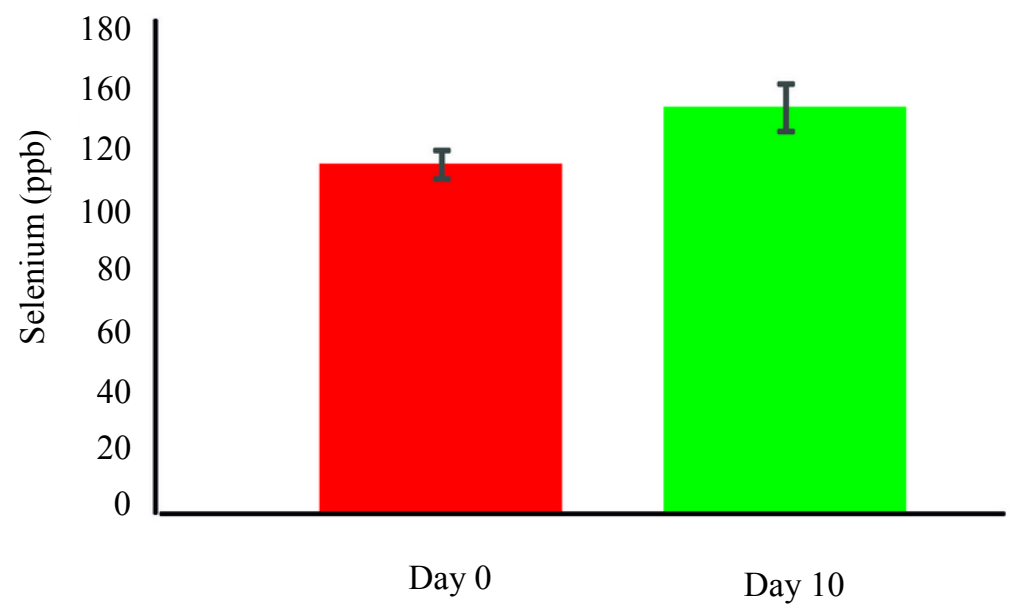

Fig. 4: Selenium blood levels (ppb) in calves before and the day after the selenium-enriched yeast supplementation 


\section{Scaling up the Selenium-Enriched Kluyveromyces Biomass Production}

In order to scale up the selenium-enrichedKluyveromyces biomass production, fermentation cultures were performed in a stirred-tank bioreactor by a process consisting of 2 repetitive batch cultures. A $K$. marxianus DSM 11954 culture was inoculated into $5 \mathrm{~L}$ of the selected whey-based culture medium (whey, $\left(\mathrm{NH}_{4}\right)_{2} \mathrm{SO}_{4}$ and $\left.\mathrm{K}_{2} \mathrm{PO}_{4}\right)$ supplemented with $20 \mu \mathrm{g} / \mathrm{mL}$ of $\mathrm{Na}_{2} \mathrm{SeO}_{3}$ in a 6 L BioFlo 110 bioreactor. Batch fermentation was carried out under the following conditions: $30^{\circ} \mathrm{C}, \mathrm{pH} 6.0$, constant agitation of $1000 \mathrm{rpm}$ and air supply of 1 LLM. After $36 \mathrm{~h}$ of batch fermentation a spike of dissolved oxygen was generated since the carbon source was completely consumed. At that moment, the biomass achieved a maximum level of $19.5 \mathrm{~g} \mathrm{DCW} / \mathrm{L}$ and therefore, a second batch fermentation was initiated. Hence, a volume of $4 \mathrm{~L}$ of culture was removed from the bioreactor and centrifuged at $3500 \mathrm{~g}$ for $20 \mathrm{~min}$ to recover the biomass. Four fresh whey-based culture medium liters were added to the bioreactor, starting another batch culture with the same conditions as described below. At the end of the process, a total of $550 \mathrm{~g}$ Wet Cell Weight (WCW) was obtained. Selenium concentration was $85 \mathrm{mg} / \mathrm{kg}$ yeast.

\section{Enriched Selenium Yeast Supplementation in Calves}

To study the effect of selenium-enriched yeast supplement on selenium blood level, 6 calves received 7 $\mathrm{g}$ of wet selenium-enriched K. marxianus (corresponding to $0.60 \mathrm{mg}$ selenium/animal/day) during 10 days. Blood selenium was measured before and after the supplementation treatments. The yeast biomass was mixed in a small amount of grains and given to the animals before they were fed. As expected, calves showed no signs of reluctance to food supplemented with yeast biomass. The level of selenium in blood, after ten days of supplementation with selenium-enriched $K$. marxianus biomass, experienced a statistically significant $(p=0.0053)$ increase of $19.2 \mathrm{mg} / \mathrm{L}$. The mean at the endpoint was $144.8 \mathrm{mg} / \mathrm{L}(\mathrm{SD}=11.5 \mathrm{mg} / \mathrm{l})($ Table 4$)$. The statistical analysis showed that blood selenium after treatment was significantly higher than those at day 0 .

Since we were interested in yeast biomass as feed supplementation, we furthermore analyzed the amino acid composition of the $K$. marxianus biomass obtained from culture grown in the selected medium (whey, $\left(\mathrm{NH}_{4}\right)_{2} \mathrm{SO}_{4}$ and $\left.\mathrm{K}_{2} \mathrm{PO}_{4}\right)$. As shown in Table 2, K. marxianus presents a relatively high methionine concentration (1.1 g/100 g protein).
Table 2: Amino acid concentration (g/100 g protein) of Kluyveromyces marxianus DSM 11954 grown in whey-based culture medium (whey, $\left(\mathrm{NH}_{4}\right)_{2} \mathrm{SO}_{4} 0.5 \%$ and $\mathrm{K}_{2} \mathrm{PO}_{4} 0.1 \%$ )

\begin{tabular}{lc}
\hline Amino acid & (g /100 g protein $)$ \\
\hline Aspartic Acid + Asparagine & 9.8 \\
Glutamic + Glutamine & 18.1 \\
Glycine & 3.8 \\
Serine & 5.6 \\
Threonine & 5.5 \\
Histidine & 2.3 \\
Tirosine & 2.6 \\
Arginine & 5.0 \\
Alanine & 6.7 \\
Methionine & 1.1 \\
Valine & 3.3 \\
Tryptophan & 0.2 \\
Phenylalanine & 0.2 \\
Isoluecine & 3.8 \\
Leucine & 3.3 \\
Lysine & 9.4 \\
Proline & 4.7 \\
Hydroxyproline & 0.0 \\
Ornitine & 0.8 \\
Taurine & 0.0 \\
Cystine + Cysteine & 4.3 \\
\hline
\end{tabular}

\section{Discussion}

Although whey can be dried and used in different products, sometimes it is not a viable alternative since the drying process is expensive in terms of energy. Therefore, it is important to develop an alternative use that generates a new product on the one hand and reduces the pollution by its untreated waste on the other hand. Therefore, we proposed the selenium-enriched yeast (Kluyveromyces marxianus) production through a whey-based culture media. Yeast biomass produced as "Single Cell Protein (SCP)" is the final product of cell mass grown in large scale culture systems. When SCP is harvested, it can be used for protein supplementation or as in our trial- as mineral organic supplementation in livestock. This system presents two advantages: first its high productivity and second its non-toxic nature as $K$. marxianus is recognized as a GRAS microorganism. This biotechnology application could be successfully applied when different kinds of industrial wastes are used as substrates, as has been reported using a poultry slaughterhouse wastewater to produce Rhodocyclus gelatinosus reducing the chemical oxygen demand (Ponsano et al., 2003).

In the present work, first we studied the $K$. Marxianus and $K$. lactis growth rate in a whey-based culture. We observed a higher growth rate of $K$. Marxianus compared to $K$. lactis. This might be the consequence of a lower capacity of the latter to incorporate lactose from the culture. Since the purpose of this work was to produce Kluyveromyces biomass enriched with selenium using a 
lactose-based culture medium, we continue our studies with $K$. marxianus strain.

It has been reported that yeasts are hypersensitive to sodium selenite; high concentrations of Se lead to DNA damage when the cells are growing in the exponential phase (Izquierdo et al., 2010). Studying different sodium selenite concentration, we did not observe an inhibition of $K$. marxianus growth. However, a decrease of the maximum level of biomass was observed adding 30 $\mu \mathrm{g} / \mathrm{mL}$ of $\mathrm{Na}_{2} \mathrm{SeO}_{3}$ to the medium compared to the other three concentrations tested. We scaled up the production and we obtained $61 \mathrm{~g} \mathrm{WCW} / \mathrm{L}$ with $85 \mathrm{mg}$ selenium per $\mathrm{kg}$ yeast. Finally, the SCP was used to supplement six calves. $K$. marxianus presents a relatively high methionine $(1.1 \mathrm{~g} / 100 \mathrm{~g}$ protein) concentration which contributes to the selenium binding capacity. This concentration agrees with previous ones reported in $K$. marxianus (Páez et al., 2008) and shows to be higher from those reported in Saccharomyces Cerevisiae (0.6g/100g protein) (Chiao and Peterson, 1953). Chemical and genetic modifications of yeast strain were reported to increase natural methionine concentration, e.g. mutant Candida Tropicalis increases from 0.42 to $0.49 \%$ methionine concentration (Halasz and Lasztity, 1991). In this context, $K$. marxianus shows a naturally high methionine concentration as well as lysine (9.4 $\mathrm{g} / 100 \mathrm{~g})$. Both amino acids are supplements in cows therefore, $K$. marxianus SCP might be used as a protein supplementation.

We conclude that our process was successful as the tested calves blood showed increased selenium after 10 days of supplementation.

\section{Conclusion}

Whey is a product of high biological value that is often discarded in cheese factories. In this study, whey was used to produce selenium-enriched Kluyveromyces. Even when organic selenium is commercially available in the form of Saccharomyces cerevisiae, there are several advantages in the use of Kluyveromyces as organic supplementation. Selenium replaces sulfur and binds to sulfur-containing amino acids such as methionine and cysteine. Kluyveromyces showed a $1.1 \%$ methionine and $4.3 \%$ cysteine concentration. These values are higher than those reported in Saccharomyces cerevisiae (Watson, 1976). Therefore, Kluyveromyces has an increased potential to bind selenium. In addition, Saccharomyces needs glucose as a carbon source since it does not express lactase. On the other side, Kluyveromyces species express lactase (Tovar-Castrom et al., 2008) and, as we showed here, they can grow optimally in a whey-based culture medium. Here we showed that after supplementing calves with selenium-enriched Kluyveromyces biomass for 10 days, the selenium level in blood increased. In conclusion, whey proves to be an efficient and economical media for the production of selenium-enriched yeast and $K$. marxianus represents a valuable feeding supplement for calves. It is important to find new alternatives for the reuse of agricultural by-products. In this sense, we believe that our research constitutes a contribution.

\section{Acknowledgment}

Authors would like to thank Facultad de Agronomía, Universidad Nacional de La Pampa and Laboratorio Weizur for partially funding this project. We also thank Lic. Ana Paez for carefully proofreading of the manuscript.

\section{Conflict Of Interest}

The authors declare no conflict of interest.

\section{References}

Amado, I., J. Vázquez, L. Pastrana and J. Teixeira, 2016. Cheese whey: A cost-effective alternative for hyaluronic acid production by Streptococcus zooepidemicus. Food Chem., 198: 54-61.

DOI: 10.1016/j.foodchem.2015.11.062

Andrews, E., W. Hartley and A. Grant, 1968. Seleniumresponsive diseases of animals in New Zealand. N Z Vet J., 16: 3-17.

DOI: $10.1080 / 00480169.1968 .33738$

Beckett, G., F. Nicol, P. Rae, S. Beech and Y. Guo et al., 1993. Effects of combined iodine and selenium deficiency on thyroid hormone metabolism in rats. Am. J. Clin. Nutr., 57: 240-243. DOI: $10.1093 / \mathrm{ajcn} / 57.2 .240 \mathrm{~S}$

Brennan, K., W. Burris, J. Boling and J. Matthews, 2011. Selenium content in blood fractions and liver of beef heifers is greater with a mix of inorganic/organic or organic versus inorganic supplemental selenium but the time required for maximal assimilation is tissuespecific. Biol. Trace. Elem. Res., 144: 504-516. DOI: $10.1007 / \mathrm{s} 12011-011-9069-\mathrm{y}$

Chiao, J. and W. Peterson, 1953. Yeasts, Methionine and Cystine Contents. J. Agric. Food Chem. 1: 1005-1008. DOI: 10.1021/jf60016a006

Fairweather-Tait, S., F. Collings and R. Hurst, 2010. Selenium bioavailability: current knowledge and future research requirements. Am. J. Clin. Nutr., 91: 1484S-1491S. DOI: 10.3945/ajen.2010.28674J

Gil, S., S. Hevia, M. Dallorso and S. Resnizk, 2004. Selenium in bovine plasma, soil and forage measured by neutron activation analysis. Arq. Bras. Med. Vet. Zootec., 56: 264-266.

DOI: $10.1590 / \mathrm{S} 0102-09352004000200018$

Gleed, P., W. Allen, C. Mallinson, G. Rowlands and B. Sansom et al., 1983. Effects of selenium and copper supplementation on the growth of beef steers. Vet. Rec., 113: 388-392. DOI: 10.1136/vr.113.17.388 
Halasz, A. and R. Lasztity, 1991. Use of yeast biomass in food production. CRC Press. Florida, USA.

Hall, J., R. Van Saun, G. Bobe, W. Stewart and W. Vorachek et al., 2012. Organic and inorganic selenium: I. Oral bioavailability in ewes. J. Anim. Sci., 90: 568-576. DOI: 0.2527/jas.2011-4075

Izquierdo, A., C. Casas and E. Herrero, 2010. Seleniteinduced cell death in Saccharomyces cerevisiae: Protective role of glutaredoxins. Microbiology, 156: 2608-2620. DOI: 10.1099/mic.0.039719-0

Julien, W., H. Conrad, J. Jones and A. Moxon, 1976. Selenium and vitamin $\mathrm{E}$ and incidence of retained placenta in parturient dairy cows. J. Dairy Sci., 59: 1954-1959.

DOI: $10.3168 /$ jds.S0022-0302(76)84468-2

Klis, F., A. Boorsma and P. De Groot, 2006. Cell wall construction in Saccharomyces cerevisiae. Yeast, 23: 185-202. DOI: 10.1002/yea.1349

Mirlean, N., E.R. Seus-Arrache and O. Vlasova, 2018. Selenium deficiency in subtropical littoral pampas: Environmental and dietary aspects. Environ. Geochem. Health, 40: 543-556. DOI: $10.1007 / \mathrm{s} 10653-017-9951-4$

Moeini, M., H. Karami and E. Mikaeili, 2009. Effect of selenium and vitamin E supplementation during the late pregnancy on reproductive indices and milk production in heifers. Anim. Reprod. Sci., 114: 109114. DOI: 10.1016/j.anireprosci.2008.09.012

National Research Council, 2001. Nutrient Requirements of Dairy Cattle: Seventh Revised Edition (2001). Washington, DC: The National Academies Press.

Páez, G., E. Jiménez, Z. Mármol, J. Ferrer and B. Sulbarán et al., 2008. Perfil de aminoácidos de la proteína unicelular de Kluyveromyces marxianus var. marxianus. Interciencia, 33: 297-300.
Ponsano, E., P. Lacava and M. Pinto, 2003. Chemical composition of Rhodocyclus gelatinosus biomass produced in poultry slaughterhouse wastewater. Braz. Arch. Biol. Techn., 46: 143-147. DOI: $10.1590 / \mathrm{S} 1516-89132003000200001$

Salman, S., D. Dinse, A. Khol-Parisini, H. Schafft and M. Lahrssen-Wiederholt et al., 2013. Colostrum and milk selenium, antioxidative capacity and immune status of dairy cows fed sodium selenite or selenium yeast. Arch. Anim. Nutr., 67: 48-61. DOI: 10.1080/1745039X.2012.755327

Slavik, P., J. Illek, M. Brix, J. Hlavicova and R. Rajmon et al., 2008. Influence of organic versus inorganic dietary selenium supplementation on the concentration of selenium in colostrum, milk and blood of beef cows. Acta. Vet. Scand., 3: 43. DOI: 10.1186/1751-0147-50-43

Smith, P., A. Tappel and C. Chow, 1974. Glutathione peroxidase activity as a function of dietary selenomethionine. Nature, 247: 392-393. DOI: $10.1038 / 247392 \mathrm{a} 0$

Tovar-Castrom, L., M. García-Garibay and G. SaucedoCastañeda, 2008. Lactase production by solid-state cultivation of Kluyveromyces marxianus CDBBL 278 on an inert support: Effect of inoculum, buffer and nitrogen source. Appl. Biochem. Biotechnol., 151: 610-617. DOI: 10.1007/s12010-008-8268-2

Watson, T.G., 1976. Amino-acid pool composition of Saccharomyces cerevisiae as a function of growth rate and amino-acid nitrogen source. J. Gen. Microbiol., 96: 263-8.

World Bank Group, 1998. Pollution Prevention and Abatement Handbook, 1998: Toward Cleaner. The International Bank for Reconstruction and Development, Washington. 